\title{
Gênero, cuidado e envelhecimento: um estudo sobre um grupo de mulheres idosas praticantes de pilates em Buenos Aires (AR)
}

Silvana Maria Bitencourt ${ }^{2}$

\section{Resumo}

0 artigo trata de uma investigação realizada com um grupo de mulheres idosas praticantes de pilates e tem como objetivo principal investigar como mulheres idosas cuidam-se na contemporaneidade. A metodologia utilizada consistiu em um trabalho de campo com aplicação de entrevistas semiestruturadas. Conforme dados obtidos, constatou-se que a grande maioria decidiu fazer atividades físicas por indicação médica. Contudo, a possibilidade de estar cuidandose com outras mulheres contribui para estas despertarem-se para o autoconhecimento de seus corpos/emoções.

\section{Palavras-chave}

Mulheres. Envelhecimento. Cuidados.

\begin{abstract}
The paper deals with an investigation conducted with a group of elderly women who practice Pilates, and its main objective is to investigate how elderly women take care of themselves in contemporary times. The methodology used consisted of field work with the application of semistructured interviews. According to the data obtained, it was found that the vast majority decided to do physical activities on medical advice. However, the possibility of selfcare with other women contributes to their awakening to self-knowledge of their bodies/emotions.
\end{abstract}

\section{Keywords}

Women. Aging. Care.

\footnotetext{
2 Doutora e Mestre em Sociologia Política pela Universidade Federal de Santa Catarina. Email: silvanasocipufmt@gmail.com.
} 


\section{Introdução}

Na contemporaneidade, os indivíduos têm-se decidido cada vez mais por práticas de cuidado, a fim de administrar da melhor forma tempos3 que compreendem suas existências em diferentes situações da vida cotidiana (MELUCCI, 1977; LISDERO et al. 2017). Muitas dessas práticas, além do objetivo de manterem a saúde do corpo, dão para alguns indivíduos a possibilidade de perceberem melhor seus sentimentos e suas emoções e, assim, gerenciá-los em situações potencialmente difíceis, como "perdas4", que tendem a afetar as suas subjetividades e influenciar tanto a vida cotidiana quanto o que se denomina projeto de vida. (MELUCCI, 1996, 2016).

No entanto, apesar de poder ser uma medida preventiva para lidar com situações difíceis, essa tendência de alguns indivíduos trabalharem o "tempo interior" por meio de seus corpos ocorre especialmente em momentos de crises, vivenciados a partir de mudanças significativas, que, de alguma forma, foram importantes para despertarem a consciência sobre si mesmos. Deste modo, segundo Melucci (1996), surge a necessidade de se repensar a maneira de lidar com a realidade cotidiana e a contemplação da vida, uma vez que os modelos de pensamento que eram seguidos no passado5 não conseguem mais suprir a realidade posta pelo momento presente, consequentemente, o indivíduo terá conflitos internos, pois precisará reprogramar a vida cotidiana, assim como as suas emoções e sentimentos para viver esse novo período da vida.

Essas mudanças que podem ocorrer em vários períodos da vida, para as mulheres ocidentais na velhice, podem afetar ainda mais seus sentimentos e emoções na medida em que elas tiveram as suas identidades de gênero socialmente construídas por atributos corporais. Sendo assim, historicamente, temos a ideia da competição com as mulheres mais jovens, críticas às mulheres pautadas em discursos morais e as associações ao corpo da mulher feitas a

${ }^{3}$ Refiro-me ao "tempo social" e ao "tempo interior", o primeiro é mensurado, é o tempo da produtividade, sendo que o tempo interior é o tempo da experiência subjetiva, ele não pode ser mensurado, é o tempo que cada um vivencia interiormente a partir das experiências e dá significado conforme percebe as suas emoções. Para mais informações, ver Melucci (1996).

${ }^{4} \mathrm{O}$ envelhecimento, apesar dos avanços da ciência e da tecnologia para lidar com o corpo envelhecido, também está associado a perdas, por exemplo, para as mulheres, a menopausa ainda tende a ser considerada um momento de mudança identitária para muitas mulheres. (FERNANDES; GARCIA, 2010; MARTIN, 2006).

${ }^{5}$ Neste texto estou entendendo o tempo e as crises a partir dos períodos relativos aos ciclos da vida, períodos em que os indivíduos vivenciam mudanças corporais e subjetivas mais bruscas, alguns desses períodos têm sido mais evidenciados na adolescência e na velhice. 
partir da construção binária. Logo, na velhice, surgem outros discursos influenciados/influenciadores por essa construção social que impactam as vidas das mulheres, como o discurso médico, a política de regimes corporais, a "luta" para parecerem mais novas e para manterem a ideia de serem "desejadas".

Todavia, o contexto atual tem apresentado melhores condições para as mulheres refletirem sobre esses atributos corporais, que nutriram durante um longo período a participaçao delas em sociedade e, consequentemente, a invisibilidade do corpo quando não dispõe mais desses atributos, digo o corpo envelhecido.

\section{Envelhecimento das mulheres}

Na cultura Ocidental, os corpos femininos historicamente estiveram associados a sua capacidade reprodutiva, além de a beleza juvenil ser significativamente valorizada (GUERRA, 2017; PINTO, 2017; IACUB, 2008). Nesse sentido, mulheres velhas tornaram-se invisíveis nesse contexto, por não corresponderem ao modelo de feminilidade socialmente representado. $\mathrm{Na}$ atualidade, esse padrão feminino pautado na beleza juvenil é reforçado pela indústria da beleza e farmacêutica, meios de comunicação e publicidade, pois para uma sociedade que vive da imagem, os sinais do envelhecimento precisam ser retocados por meios reais (como cirurgias e técnicas que prometem rejuvenescimento) e aplicativos para smatphones que filtram qualquer coisa que possa lembrar um corpo naturalmente velho. (SIBILIA, 2012).

Partindo dessa perspectiva, o envelhecimento, quando chega para as mulheres, chega de diversas maneiras e em diversos tempos vividos em suas biografias, influenciando diretamente nas suas subjetividades, enquanto identidade de gênero socialmente construída por meio de atributos corporais (NASCIMENTO, 2011; BRITTO DA MOTTA, 2002; FERNANDES; GARCIA, 2010).

No mercado dos afetos, as transformações corporais trazem essas desvantagens para as mulheres mais velhas, que terão que competir com as mais jovens por seus potenciais parceiros, sejam eles da mesma faixa etária, mais jovens ou mais velhos (BOZON, 2004). Conforme Sontag (1972), muitas mulheres tendem a mentir a idade, pois, com o envelhecimento, não perderam somente a aparência jovem, mas suas aparências tendem a ser de pessoas mais velhas que seus potenciais parceiros. Diferentemente dos homens mais velhos 
que se relacionam com parceiras mais jovens, mulheres mais velhas, quando decidem se envolver com parceiros mais jovens, podem ser alvo de críticas pautadas em discursos morais e denominações pejorativas, como "viúva alegre", "velha safada" etc. (NASCIMENTO, 2011).

Na construção do masculino e feminino na cultura ocidental, podemos verificar como os papéis sociais de homens e mulheres dicotomizaram masculinidade e feminilidade. A partir de uma construção binária, as mulheres tiveram seus corpos associados ao mundo doméstico e da reprodução da vida, ao passo que os homens, ao mundo público, do trabalho, da cultura, ou seja, da produção (ORTNER, 1979). Junto a isso, a atração pela jovialidade, virgindade e desfloramento faz com que as mulheres jovens sejam desejáveis, enquanto "as panelas velhas fazem comida boa", para citar a canção popular que enfatiza o lar como lugar de mulher.

É importante considerar que o envelhecimento é um processo que ocorre visivelmente no corpo, podendo afetar os sentimentos e as emoções de indivíduos de ambos os gêneros, mas o processo de construção da identidade é distinto, uma vez que mulheres e homens envelhecem de modo diferente (BRITTO DA MOTTA, 2002; YURI; URBANO, 2008; GOLDENBERG, 2010; FERNANDES; GARCIA, 2010).

Sobre o envelhecimento feminino, a menopausa foi considerada a porta de entrada da "construção do envelhecimento das mulheres a partir da retirada dos encantos da sua beleza corporal e ainda para o declínio de sua sexualidade" (FERNANDES; GARCIA, 2010, p. 406). A mulher reduzida dos seus atributos corporais é signo do poder masculino e de seu status social, de modo que, ao perder esses atributos, passaria a ser um "corpo invisível", considerando a linguagem depreciativa das "perdas" dada ao corpo menopausado, quando analisado a partir do discurso médico. Tal discurso aciona a necessidade de medicalização e controle sobre essas "perdas", analisando a menopausa mais do âmbito fisiológico do que um fenômeno com significados determinados culturalmente a partir do poder/saber médico sobre os corpos das mulheres (MARTIN, 2006; GUERRA, 2017). De acordo com Suaya (2015, p. 621),

En relación al cuerpo femenino la menopausia es una de las condiciones biológicas que afectan subjetivamente a las mujeres y las solicitan a reconocerse como viejas. La pérdida de su fertilidad aparece como un rito de pasaje que, en algunos casos, puede suscitar grandes montos de sufrimiento psíquico. 
Nas sociedades ocidentais, a dicotomia que estruturou as relações de gênero dividiu simbolicamente o pensamento, a linguagem, que se sustenta a partir de uma hierarquia, cuja assimetria revela "modelos de pensar e sentir" para homens e mulheres. Dentro dessa perspectiva, há uma política de regimes corporais e destinos corporais para homens e mulheres. Kogan (2011) faz uma análise sobre envelhecimento em uma perspectiva de gênero a partir do pensamento de Jean Baudrillard. A autora afirma que os corpos das mulheres são mais telas, simulacros do que detentores de uma materialidade concreta. A autora mostra que, diferentemente da materialidade dos corpos dos homens, os das mulheres não têm materialidade, eles são telas para serem olhados, examinados e, consequentemente, julgados: "esos cuerpos femeninos son experimentados como problemáticos en la medida en que no se consideraran atractivos, no se los cuida por el excesso de trabajo o se gana peso" (KOGAN, 2011, p. 22). No entanto, podemos acrescentar que, além de serem olhados em sua imaterialidade imaginada, sua materialidade se sobressai nos inúmeros casos de violência contra mulher, incluindo estupros e feminicídios, pois o corpo, seja no que tem de imaterial e no que tem de material, não é propriedade daquela que o porta.

Dentre as várias violências simbólicas ou não referentes e atuantes à corporalidade feminina, vemos que o envelhecimento feminino pode estar vinculado à ideia de sofrimento, a partir desse enfoque ${ }^{6}$ sobre envelhecimento e gênero pautado na dupla exclusão, ou seja, "ser mulher e velha". Pode-se perceber que as mulheres de meia idade, aquelas que estão mais próximas do processo de menopausa, entre a faixa dos 40-50 anos, começam a vivenciar o processo de envelhecimento de forma mais evidente, ocorrendo não apenas mudanças físicas visíveis, mas também alterações subjetivas, que revelam um momento de crises e de necessidade de reelaborar suas identidades (GOLDENBERG, 2010; GUERRA, 2017). Outrora, eram as balzaquianas, as mulheres de trinta anos que sofriam as transformações mais intensamente, o

\footnotetext{
${ }^{6}$ Debert (2013) disserta sobre os diversos enfoques que tratam o envelhecimento em uma perspectiva de gênero; para a autora, não há um ganhador e um perdedor com a idade, mas há abordagens que vitimizam a mulher a partir do envelhecimento, sendo dupla a discriminação "ser mulher e velha"; há outras que os homens sofrem mais por se aposentarem e não afirmarem mais a sua masculinidade a partir do ser provedor; e há outros enfoques ainda que mostram que há uma inversão dos papéis de gênero. Para essa autora, a velhice pode ser vivida e compreendida de diversas maneiras, considerando a contribuição das pesquisas históricas e antropológicas. Neste trabalho, tenho como hipótese que as mulheres velhas têm mais desvantagens que os homens velhos, pois tendem estes últimos a ter menos tempo destinado ao autocuidado.
} 
que nos permite relativizar o etarismo para além das cronologias dos aniversários completados.

As sociedades contemporâneas, especialmente as latino-americanas, cultuam a beleza e a juventude. Raphael Bispo (2016), ao analisar os discursos de mulheres que foram dançarinas do apresentador Chacrinha, no Brasil, constatou que as mulheres que hoje estão com seus 60-65 anos se vangloriam quando são identificadas com idades cronológicas inferiores a sua idade real. Desse modo, muitas mulheres idosas "lutam" contra o tempo para parecerem mais novas.

Na Argentina, "ser mãe e ser casada" são atributos que, embora não sejam mais o destino para a maioria das mulheres, estão enraizados na cultura argentina (NARI, 2000, DREIER, 1920 apud LUCIANI, 2010). Há toda uma dimensão histórica e política do contexto deste país que se reconhece a partir da maternidade e do casamento, logo da mulher que sabe cuidar e compromete-se para desempenhar essa função nas famílias argentinas (LOPÉZ, 2011).

A ideia de beleza feminina neste país tem como referência um corpo branco, jovem e magro, logo esta referência pode excluir muitas que não se enquadram nesse padrão, como as idosas, as gordas e não brancas (ROCA, 2003; PINTO, 2017). Considerando que na contemporaneidade a indústria da beleza e de cosméticos em parceria com os meios de comunicação tem um papel influenciador para as mulheres de camadas médias (ROCA, 2003). Paula Pinto (2017), que pesquisou cerca de cem mulheres de várias idades, trajetórias de vida e perfis socioeconômicos na América Latina, constatou que as mulheres, à medida que envelhecem, começam a vivenciar mais a solidão. Conforme a pesquisadora, a mulher pós-50 anos, independentemente da classe social, não se sente mais inserida, por exemplo, no mercado da moda, e vivencia maiores dificuldade de ter um relacionamento afetivo.

O estudo realizado por Nascimento (2011) sobre mulheres idosas que dançam comprova a influência dos dispositivos morais, que agem sobre o comportamento de mulheres idosas de uma geração que hoje estão com mais de 60 anos. A autora constatou que, ao mesmo tempo que as mulheres falavam que a dança contribuía para sentirem autoestima e autonomia em relação ao uso do corpo na velhice, essas mulheres recusavam a ideia de serem corpos desejados. Segundo a autora, a ideia de serem "desejadas" seria prejudicial à imagem de mães e avós dedicadas ao cuidado de suas famílias, que estas mulheres achavam importante preservarem para os outros. 
Vale a pena salientar que, na Argentina, o envelhecimento é um fenômeno vivenciado atualmente por mais mulheres que homens (TISNÉS; SALAZARACOSTA, 2016 ; ODDONE, 2014a). Contudo, as condições de elas vivenciaremno apresentam desvantagens. Além de sofrerem mais com as marcas do envelhecimento, em uma sociedade movida pela imagem (SIBILIA 2012; ROCA, 2003; KOGAN, 2011), também são as que mais sofrem discriminação no mercado de trabalho, limitações para terem acesso à seguridade social e, por viverem mais, sofrem mais de doenças crônicas degenerativas. Além disso, por passarem a vida toda cuidando da família, no final da vida, poucas terão membros familiares com tempo disponível para cuidar delas, logo "aquela que cuida não tem sido cuidada".

Considerando que o trabalho de cuidado historicamente tem ficado sob encargo das mulheres, a partir das diversas condições que as posicionam na família como mães, filhas, esposas e noras, esse atributo de ser cuidadora tem sido uma discussão recorrente nos estudos feministas (HIRATA; GUIMARÃES, 2012; LÓPEZ et al., 2011).

As mulheres historicamente tiveram seus corpos destinados ao trabalho reprodutivo, o qual possibilitou a elas desenvolver conhecimentos e técnicas de como cuidar "do outro". Partindo dessa ideia, as mulheres têm sido socialmente representadas como cuidadoras potenciais na esfera doméstica (incluindo o cuidado dos filhos, da casa, além de muitas serem responsabilizadas pelo cuidado dos pais quando envelhecem). Nesse sentido, o cuidado é um trabalho que abarca além da dimesão cognitiva, prática, também a dimensão relacional, emocional e sexual de quem cuida e é cuidado, portanto, envolve sentimentos e emoções (SOARES, 2012).

De acordo com López et al. (2011), na Argentina, a partir de 1970, a queda das taxas de mortalidade e natalidade leva Buenos Aires ao predomínio do modelo de reprodução humana, que consiste em uma maternidade mais tardia e menos prolífica, sendo também uma tendência para as classes mais baixas. Assim, com a fecundidade abaixo do nível de substituição, considerando-se também o aumento da expectativa de vida, ocorre o crescente envelhecimento da população.

Partindo dessa perspectiva, a decisão sobre o cuidado do corpo tem ocorrido por significativa influência dos profissionais da saúde, mas também por informações que circulam nas redes sociais, os programas sociais, que se pautam no discurso da "qualidade de vida" da população idosa. Do mesmo

${ }^{7}$ Embora haja muitas críticas ao conceito de qualidade de vida como descontextualizado da realidade da maioria dos idosos, Nunes e Duarte (2011) associam a qualidade de vida a uma 
modo, o aumento da expectativa de vida da população tem sido um dado que contribui para a sociedade e o Estado elaborar e executar políticas ${ }^{8}$, que visem ao cuidado dessa população que envelhece.

Nesse sentido, alguns estudos (FERREIRA; FIGUEIREDO, 2007) comprovam a influência que esses programas têm exercido na vida da população idosa de como fazer exercícios físicos para cuidar da saúde, a fim de ter uma "boa qualidade de vida" na velhice. O discurso da terceira idade assumido pelos gerontólogos, muitas vezes, apresenta-se descontextualizado da realidade da maioria dos idosos, logo, tende a homogeneizar o envelhecimento como um processo vivenciado igualmente por todos/as. Esse discurso é problemático para diversos autores/as que complexificam socioantropologicamente a ideia de envelhecer como um fenômeno que deve considerar os diversos marcadores sociais e a própria faixa etária dos/as idosos/as que, dependendo da idade, necessitarão de cuidados diferenciados (BRITTO DA MOTTA, 2002; BRIGUEIRO, 2005; DEBERT, 2013; ODDONE, 2014a; 2014b; SILVA, 2016, entre outros).

Também podemos perceber que a busca por terapias faz parte do cenário contemporâneo, no qual o indivíduo decide por um "tempo para si", para cuidar-se. Melucci (2016) comprova que muitos indivíduos, depois de terem passado por problemas emocionais que eram identificados como exclusivamente sociais por eles/as, buscam esses suportes para se autoconhecerem a fim de curarem-se.

Algumas pesquisas baseadas em dados empíricos atuais constataram que a grande maioria dos idosos que procura fazer alguma atividade física periódica durante a semana é composta por mulher (NUNES; DUARTE, 2011; MENEZES; FROTA, 2012). Desse modo, as mulheres que serão apresentadas neste estudo são as que se decidiram por dedicar um tempo para se cuidarem, ainda que o significado do cuidado possa ser amplo e dissensual.

Pensando o cuidado do corpo como um momento de interação entre as mulheres, considerando que este expressa em seus movimentos aspectos da

perspectiva holística de ser humano, sendo que a prática de exercícios físicos é considerada fator relevante para se conquistar uma melhor qualidade de vida (p. 232).

${ }^{8}$ Atualmente, podem-se verificar diversos programas sociais que abarcam a ideia de envelhecimento ativo na cidade de Buenos Aires. Para mais informações, ver: Personas Mayores: Conocé los programas que la Ciudad tiene para cuidar, asistir y promover la integración y el envejecimiento activo de los adultos mayores.

<https://www.buenosaires.gob.ar/desarrollohumanoyhabitat/personas-mayores>Acesso em: $1^{\circ}$ maio 2019. 
subjetividade feminina, este trabalho tem como objetivo principal investigar como mulheres idosas argentinas cuidam-se na contemporaneidade. Nesse sentido, analisaremos como partiu a decisão do cuidado, os investimentos, as influências e as reflexões dessas mulheres sobre o envelhecimento feminino vivenciado na atualidade.

\section{A metodologia}

Em relação à metodologia utilizada, realizei um trabalho de campo em uma academia de pilates9 de Buenos Aires10 e entrevistas semiestruturadas em caráter de profundidade com 10 mulheres com idades entre 60 e 82 anos que praticam pilates há mais de 10 anos. A pesquisa de campo foi iniciada em setembro de 2018, em uma academia de classe média.

Durante seis meses de observação de campo, verifiquei a frequência diária de um grupo de mulheres idosas, praticantes de pilates do horário das $8 \mathrm{~h}$ às $9 \mathrm{~h}$ da manhã, portanto, o recorte deste estudo partiu desse grupo de mulheres. Primeiramente, matriculei-me na academia para participar das aulas de pilates. Somente depois de seis práticas, consegui apresentar-me como pesquisadora para a professora e, à medida que participava das aulas, as mulheres também compreenderam que eu estava ali fazendo uma pesquisa sobre elas. Nesse sentido, conversar com a professora sobre eu estar lá para observar as aulas foi fundamental para conseguir interagir com as mulheres. A negociação do campo foi construída gradualmente, afinal, quando cheguei a essa turma, no início, elas não me cumprimentavam. Percebia que precisava passar pela prova da aceitação do grupo para realizar o trabalho de pesquisa. Depois de umas seis aulas, elas começarem a saudar-me com "Buen día", falar comigo, perguntar coisas sobre o Brasil. No entanto, eu sabia que estava em um bairro que não poderia reduzir Buenos Aires somente a partir da experiência cotidiana com essas mulheres. Nesse sentido, compartilho com Melucci (1996),

${ }^{9} \mathrm{O}$ pilates foi desenvolvido na década de 1920 por Joseph Pilates, que o fez devido aos problemas de saúde que debilitavam seu corpo, no entanto, foi somente nos anos de 1980 que houve reconhecimento internacional do pilates, sendo que, na década seguinte, ganhou popularidade significativa no campo da reabilitação (SILVA; MANNRICH, 2009). Segundo alguns estudos (SILVA; MANNRICH, 2009, FERREIRA et al. 2007), por ter como objetivo a prevenção e tratamento de agravos à saúde, o pilates não necessariamente tem como objetivo alcançar formas corporais que contemplam a cultura fitness (KOGAN, 2005).

${ }^{10}$ Buenos Aires é o distrito mais envelhecido da república da Argentina, sendo que 22\% (626, 186 personas) são pessoas com mais de 60 anos (INSTITUTO NACIONAL DE ESTADÍSTICAS Y CCENSOS, 2010). 
ao salientar que, devido à complexidade das sociedades contemporâneas e das intensas transformações e possibilidades interpretativas, é importante pontuar que se trata de fragmentos da vida de mulheres longe dos grandes eventos coletivos que podem provocar mudanças em um plano mais macro.

Em meados de março de 2019, encerrei o campo de pesquisa, finalizei as entrevistas e passei para a fase da transcrição. Nesse sentido, é importante pontuar que as minhas análises começam à medida que observo as práticas corporais dessas mulheres e construo a possibilidade de a minha observação garantir as entrevistas a partir de um roteiro predefinido. A participação das mulheres se encerrou no momento que eu verifiquei que as falas delas se repetiam, que muitos argumentos dialogavam com a literatura que havia consultado sobre cuidado e envelhecimento feminino e que, mesmo verificando diferenças entre elas, começaram a parecer muito próximas umas das outras.

As entrevistas que serão apresentadas neste texto foram analisadas a partir do método de análise de conteúdo de Lawrence Bardin (2002). Esse método qualitativo compreende o desvendamento de significações de diferentes tipos de discursos, baseando-se na inferência ou dedução, mas que, simultaneamente, respeita critérios específicos propiciadores de dados em frequência, em estruturas temáticas, entre outros. Desse modo, construí uma interpretação organizada a partir do contato com o material coletado e seu amadurecimento gradativo. A leitura atenciosa das entrevistas foi primordial para configurar um quadro sobre o grupo de mulheres analisado.

Sobre o perfil das dez mulheres entrevistadas da pesquisa, saliento que todas são mães, e seis são avós. Em relação ao estado civil, oito são casadas, uma víuva e uma divorciada. Todas praticam pilates há mais de dez anos. A grande maioria das entrevistas foi gravada em um café ao lado da academia e durou de 1 a 1 hora e meia. Em relação à classe social das entrevistadas, todas são de classe média, têm grau de instrução superior e declaram-se brancas. Em relação à religião, sete são católicas e três espíritas. A seguir, apresento os resultados e a discussão de temáticas que foram abordadas nas entrevistas a partir do envelhecimento.

\section{A decisão e as influências para o cuidado}

O envelhecimento primeiramente ocorre na pele, perde-se colágeno, elasticidade, a musculatura vai ficando flácida, logo surgem linhas de expressão e rugas. Assim os primeiros sinais do envelhecimento vão 
aparecendo e, a partir dessas transformações, vão se construindo as novas necessidades de cuidados. Contudo, essa necessidade é vivenciada de modo diferente, pois cada corpo deve ser analisado a partir da classe social, como afirma a entrevistada A, 62 anos, "si la persona es rica puede ser vivida más tranquilamente cuando se enferma, que cuando se es pobre". Na análise sobre o envelhecimento além do gênero, deve-se considerar a presença de outros marcadores sociais que podem também influenciar no processo de envelhecer. (GIDDENS, 2005; SILVA, 2016; ODDONE, 2014a, 2014b).

Luc Boltanski (1979) destacou, em seu estudo sobre corpo e classe social, que o cuidado com a saúde do corpo carrega significados distintos, conforme a classe social. Nesse sentido, é importante salientar que as mulheres participantes desta pesquisa são todas de classes médias e com curso superior completo, aspectos que devem ser levados em consideração em seus discursos.

A decisão de praticar atividade física ocorreu para a grande maioria por recomendação médica. A entrevistada B comenta que foi somente depois que seus exames médicos comprovaram que seu colesterol estava alto que começou a fazer exercícios físicos. Segundo ela, seu problema não foi adquirido por hábitos alimentares incorretos, mas por ter uma genética predisposta a ter dislipidemia. Conforme sua fala, temos:

No, yo comece a cuidarme a los 50 por que las analisis clínicos no me salian bien, mucho colesterol, nada más que eso, mucho colesterol, yo siempre fue de comer, pero no comia cosas que produciam colesterol, entonces se descobri que colesterol es como una herencia genética, entonces precisaba hacer algo para bajalo e los médicos me pediram que debia vir a ginásio. (Entrevistada B, 69 anos).

Contudo, muitas comentaram, durante as entrevistas, que decidiram praticar alguma atividade física por estarem acima do peso e sentindo-se insatisfeitas com seus corpos. A entrevistada $\mathrm{C}$ recorda que começou cedo a praticar atividades físicas, pois, desde adolescente, tinha tendência a engordar. Desse modo, a decisão também esteve atrelada a não estar se sentindo bem com seu corpo. Conforme ela,

Siempre desde chica yo era más rejenita, gordita, uns quilitos a más. Siempre me cuidava, iba mucho las medicas nutricionistas desde chica, adolescente la realidad, cuido de los poquitos quilos a más, desde chica siempre me cuide. (Entrevistada C, 60 anos). 
Nesse sentido, o corpo percebido como gordo para essas mulheres não foi apenas motivo para decidirem-se por fazer atividades físicas, mas também pela influência que um "corpo ideal" socialmente valorizado, o corpo magro, por exemplo, pode proporcionar melhor autoestima e inclusão no mercado da moda, pois há poucas tendências na moda para um corpo feminino acima do peso (SIBILIA, 2012; ZANELLO, 2018). Segundo a entrevista D, o corpo magro é o mais bonito, visto que toda roupa "cae bien". Algumas mulheres também falaram que estranhavam as brasileiras que iam à praia e, mesmo gordas, usavam biquíni; as argentinas não fazem isso, pois "las argentinas se cuidan y son más exigentes con sus cuerpos".

Durante o trabalho de campo, constatei que as mulheres chegavam mais cedo para fazer exercícios na esteira e na bicicleta. Segundo elas, esses aparelhos possibilitavam maior gasto calórico, pois os exercícios aeróbicos contribuem para "eliminar las grasas". No entanto, mesmo fazendo muitos exercícios, algumas comentaram nas entrevistas que a menopausa trouxe muitas mudanças no modo de sentir o corpo, pois agora tinham o metabolismo mais lento e mais dificuldades de emagrecer, as dietas que faziam, quando eram mais novas, não davam mais tantos resultados. Contudo, nenhuma demonstrou estar infeliz com isso, mostrando pela fala que aceitam o "novo metabolismo" mais lento. Essas mulheres também falam que sabem como seus corpos são vistos pelos "outros" por estarem praticando pilates, dizem que são vistos como corpos velhos e fracos. A entrevistada A fala sobre o público mais comum nas aulas de pilates, comenta que, quando iniciou a prática, verificou que, em geral, o público era constituído mais por mulheres e homens mais velhos, contudo lembra que, nesta turma, já houve homens gays argentinos.

Para mi es una impresión que pilates es para débiles e para personas como mujeres que son mas débiles, personas más grandes, quando empeze tenia hombres que hacia eran personas más grandes, pero a principio yo via que algunos hombres que venían eran gays, argentinos, pero cuando via arrancado me llamaba atención, o era gente grande o era gay. (Entrevistada A, 62 anos).

O pilates é visto como uma prática feminina. Mesmo tendo homens que o praticam, estes são vistos como fora do padrão de masculinidade hegemônico ${ }^{11}$

\footnotetext{
${ }^{11}$ Considerando que o padrão de masculinidade hegemônico cultuado no Ocidente são homens jovens, heterossexuais, saudáveis e com um estilo de vida pautado na liberdade e na competitividade de mercado (CONNELL, 2016).
} 
(CONNELL, 2016), pois, quando não são velhos, são gays. Além de ser uma atividade vista como pouco masculina, também teria a questão de a professora ser uma mulher, algo que poderia contrariar muitos homens que não se dispõem a receber instruções de uma mulher. O estudo de Nunes e Duarte (2011) constatou que a maior participação de idosas em atividades físicas está significativamente vinculada à construção cultural das relações de gênero, pois os homens, devido à socialização pautada no patriarcado e no machismo, não se sentiriam bem sendo conduzidos por uma professora. Assim como há um fator simbólico presente na educação física, logo os exercícios físicos não estão isentos de discursos generificantes (ALTMANN, 2015).

Vale a pena ressaltar, no entanto, que, mesmo sendo o pilates uma atividade realizada pela classe média, talvez possa ser considerado uma atividade para os não detentores de um corpo ideal, socialmente valorizado e disseminado pelos meios de comunicação e publicidade para se expressar e movimentar. Para ser um corpo valorizado, portanto desejado, não basta estar magro, precisa também ser jovem, saudável e heterossexual. Nesse cenário da academia contemporânea, que preza a cultura fitness, do corpo performar para sair performando, alguns tipos de corpos, por não atenderem a esse requisito (enquanto um estilo de vida), serão estigmatizados (GOFFMAN, 1975; KOGAN, 2005). Contudo, as mulheres idosas entrevistadas reconhecem que seus corpos não correspondem mais a um corpo fonte de atrativos de desejos masculinos, confirmando, em suas falas, o que a literatura (NASCIMENTO, 2011; FERNANDES; GARCIA, 2010; GOLDENBERG, 2010; IACUB, 2008, BRITTO DA MOTTA, 2002; ROCA, 2003; entre outras) sobre gênero e envelhecimento tende a confirmar. Mulheres, quando tiverem seus corpos envelhecidos, perderiam o potencial de despertar desejos sexuais no outro, logo se tornam corpos "invisíveis", sendo que os desejos sexuais na velhice podem ser interpretados como "anormais", "imorais" e, para alguns, vergonhosos a partir do discurso moralizante perante um corpo que não corresponde mais a um objeto de desejo. O pesquisador Iacub (2008) destaca a dificuldade de se pensar no erotismo na velhice. Para o psicológo, mais do que as limitações de ordem física ou psicológica, é o "sentimento de vergonha" diante de seus próprios corpos, pois, nas sociedades ocidentais, há uma limitação cultural de uma estética de erótico na velhice. Para as entrevistadas, com o passar da idade, os objetivos vinculados às atividades físicas são outros, ou seja, mais importante que a beleza juvenil capaz de "despertar desejos" é ter saúde para não precisar depender dos "outros". 
Para elas, houve um momento em suas vidas, depois que passaram seus períodos de gestações, cuidados com os filhos pequenos, estressante jornada de trabalho, tendo que conciliar trabalho doméstico e profissional, que resolveram "fazer algo por si", fora do espaço doméstico e do mundo do trabalho. Dizem que necessitavam de "um tempo para si". Sobre esse "tempo para si", a entrevistada E salienta: "estar bien, mas también sentirse bien, yo salgo de la clase e me sinto bien, pues yo necesito de un tiempo, mi cuerpo mi pidi, me sinto bien mentalmente" (Entrevistada E, 65 anos).

Para a entrevistada A, a atividade física lhe ajudou na construção de foco para executar as suas tarefas cotidianas, logo conhecendo melhor seu corpo para encontrar uma forma que garantisse uma melhor organização de sua vida cotidiana. Lisdero et al. (2017) constataram, em sua pesquisa sobre trabalhadores/as de camadas médias, que estas buscam técnicas como pilates, yoga, crossfit para descarregar as energias do estresse produzidas pela vivência no ambiente de trabalho. Para os autores, a prática de atividades físicas seria tomada como um estilo de vida, que contribui para os trabalhadores/as criarem mecanismos para controlar seus sentimentos e emoções para seguirem trabalhando e produzindo.

A grande maioria das mulheres, quando sente alguma sensação física ou emocional diferente, sentimentos como medo e ansiedade, buscam resultados no Google de que doença podem ter contraído. A disseminação de informações via Internet por meio da ferramenta Google tem influenciado a população nos últimos anos, muitos tendem a construir diagnósticos sobre seus estados físicos e emocionais a partir das informações em sites de saúde e canais no Youtube (MIRANDA; FARIAS, 2009).

Segundo elas, o Google contribui para visitarem sites que abordam saúde, envelhecimento e alimentação saudável, a fim de saberem formas de prevenir sinais da idade de forma mais barata e não invasiva. O cotidiano vai sendo desenhado, considerando o tempo disponível que elas têm. Para essas mulheres, não é mais o corpo que é seu "capital", mas, para elas agora, é o "tempo" que virou o capital nessa fase da vida (GOLDENBERG, 2010). Conforme a entrevistada F, seu dia começa cedo. Logo que desperta, segue uma série de recomendações que foi adquirindo lendo e conversando com seu médico:

Las seis de la mañana yo me desperto, no se puede tomar jugo que sea acido por que elimina, elimina el remedio de la tiroide, bien saludable, entonces tomo jugo no acido, despues siete menos quarto como la fruta o 
el limon con agua activia, en la siete e dez ya tomo mi mate cozido, no cafe, mate cozido con un poquito de leche descremada, dos tazas de agua e nada más y ya voy para ginasia (Entrevistada C, 82 anos).

Pode-se perceber, a partir da fala da entrevistada C, que há um programa de cuidados cotidianos realizados por ela diariamente, segue conhecimentos sobre "o que pode e o que não pode" ingerir: "no se puede tomar jugo que sea acido", segue horários específicos "las seis", "siete menos quarto", "siete y dez" e segue limites "nada más" e medida "un poquito de leche". Então o cuidado para essas mulheres dita determinadas regras. Elas buscam ter disciplina com o corpo, contudo não comentam que esses cuidados são para os outros, ou é uma luta contra o envelhecimento e a morte. O cuidado consciente revela-se como uma necessidade que descobriram em um determinado momento da vida, e todas as iniciativas de cuidar-se começaram após terem passado por longos períodos em que não tinham cuidado consigo mesmas, pois tinham que cuidar dos outros (filhos e marido).

\section{Os investimentos para cuidar-se}

À medida que o envelhecimento vai se apresentando a partir de sinais visíveis detectados no corpo, essas mulheres, além da atividade física, começam a cuidar mais da pele do rosto, usando cremes específicos para linhas de expressão e rugas. Para algumas, os cabelos brancos revelam um dos sinais mais significativos do envelhecimento, e tê-los, segundo a Entrevistada G de 61 anos, "agrega mais anos". Para muitas pode ser sinal de descuido pessoal. Além desses cuidados, elas cuidam da alimentação, ou seja, dizem que procuram comer mais frutas e verduras, pouca carne, evitam doces e frituras, mas nos fins de semana comentam que se liberam da dieta, devido aos programas familiares.

Em relação às cirurgias plásticas que prometem produzir um corpo mais jovem, elas falaram que são contra, para elas, as cirurgias "apenas mascaram sinais da idade". Elas mostraram críticas a esses procedimentos, que, dizem, muitas mulheres tendem a fazer, pois não estão felizes consigo e querem agradar o homem. Considerando que a publicidade tende a valorizar corpos de mulheres magras, jovens e brancas, a sociedade argentina, como a brasileira, também tende a valorizar a magreza e a juventude.

A respeito dos gastos destinados ao cuidado do corpo, segundo elas, o investimento compreende a mensalidade da academia e alguns cremes. $\mathrm{Na}$ 
visão da entrevistada $H$, de 67 anos, seus gastos são muito poucos, nunca vai a salão de beleza como as demais colegas da turma, que, por sua vez, falaram que também não costumavam ir. Para ela, seu corpo não lhe dá trabalho, não tem grandes preocupações com o cuidado e afirma que não acredita "em milagres", enfatiza que a maioria de suas amigas também não compartilha do consumo de produtos para postergar o envelhecimento. Segundo ela, "Toda ilusión construida por el mercado".

Elas afirmam que consultam médicos dermatologistas, ginecologistas para saber sobre os sinais de envelhecimento que foram aparecendo no corpo, especialmente após a menopausa. Contudo, dizem que, mesmo sabendo que o corpo muda e há sinais visíveis, não sofrem com isso. A entrevistada D fala sobre o cuidado diário com a sua alimentação, que vai ao médico, usa cremes e faz atividades físicas, mas destaca a importância de ter uma "buena amiga" para lhe escutar.

Empezar ter bueno caráter, ser alegre, alimentarse bem, comer de todo fruta, verdura, ir siempre aos controles médicos, e uma buena crema para la cara, hacer atividades físicas, tener uma buena amiga que te escuche, una companera (Entrevistada D, 63 anos).

Na Argentina, como toda sociedade movida pelo mercado e pelo consumo, há um padrão ideal de corpo desejado e propagado nos anúncios publicitários, e esse padrão tende a influenciar as pessoas, especialmente as mulheres. A entrevisada F, quando é abordada sobre como as argentinas cuidam-se, comenta com um olhar de reprovação pela decisão dessas mulheres em fazer cirurgias plásticas. De acordo com ela, "en los mismo que las brasilenas, cirurgias, cirurgias, cirurgias". De acordo com Iacub (2008, p.2), nesse cenário, "uma guerra é travada contra o envelhecimento do corpo, que assume a forma de uma maior necessidade de gerenciamento e uso de várias terapias contra os sinais do envelhecimento, tornando-o um objeto rígido de disciplina e um fetiche do desejo sexual".

Para elas, as mulheres bonitas não necessitam de cirurgias, a "beleza natural" e o "corpo natural" sem mudanças com cirurgas mostram-se fortemente valorizados por essas mulheres. Sobre a indústria da beleza que oferece todo um aparato para prevenir e combater o envelhecimento, algumas, durante as entrevistas, comentavam que essa indústria atinge até as mulheres pobres, estas, mesmo sem recursos para comprar os cremes que são caros, sempre pintam o cabelo, a fim de esconder os brancos. 
Em relação ao envelhecimento do corpo que vivenciam, elas apresentaram em seus discursos significativa necessidade de liberdade, dizem que o envelhecimento proporciona mais liberdade de serem livres de padrões de beleza, livres da necessidade de estarem com alguém. Nesse sentido, o ideal de feminilidade focado no mundo dos sentimentos e da necessidade de serem amadas é rompido por elas.

Durante a prática de pilates, percebi que algumas mulheres não praticavam o relaxamento final, que é feito dez minutos antes de finalizar a aula. Contudo, algumas saíam mais cedo e eu as encontrava, muitas vezes, ao lado do ginásio, tomando café e comendo medialunas. O relaxamento para as mulheres que participavam contribuía para aliviar o estresse, mas também para mexer com sentimentos e manifestar algumas emoções (choro). Contudo, nenhuma discutia ou queria saber do motivo que fez a amiga chorar durante a prática. Os sentimentos e as emoções eram experienciados de forma bastante particular e privada, ninguém conversava. De acordo com Melucci (1977, p. 76):

The body is our unique and unalienable possession which gives us the power of self-recognition in an age when other forms of identification break down. No one else can tell us what we feel within our bodies; only we can express ourselves through the body.

O corpo se apresenta como um importante recurso que permite à mulher contemporânea se conhecer. Quando todas as outras formas foram projetadas por uma sociedade que sempre buscou definir as emoções e os sentimentos femininos, esse corpo torna-se o seu "melhor amigo". Contudo, nem sempre todas estão dispostas a conhecer seus corpos.

De acordo com a entrevistada I, de 65 anos, muitas mulheres não estão preparadas para conhecer partes de seu corpo, muitas vezes, esse relaxamento pode fazer a pessoa ter que estar consigo mesma e lidar com emoções difíceis, que não estão preparadas para trabalhar no momento de suas vidas. Contudo, podemos observar contradições em seus discursos, pois, ao mesmo tempo que dizem que mostram uma disciplina para o cuidado, também saem da aula juntas para tomar café e comer medialunas antes de a aula terminar. Desse modo, o pilates também pode ser realizado para manter as ligações afetivas entre elas, talvez com a professora, pois há uma socialização como uma espécie de terapia, de tempo para si e para amigas, o que pode ser considerado também um cuidado. 


\section{A sociabilidade gerada a partir do envelhecimento}

Em relação ao tempo para a atividade física e a sua continuidade, pude constatar que essas mulheres falam que, no início, não gostavam tanto de movimentar-se, mas que, com o tempo, foram sentindo que a atividade física em grupo lhes ajudou a criar laços de amizade. Esse grupo faz pilates há mais de 10 anos e, além das aulas de pilates e demais atividades feitas na academia durante a semana, também se encontra nos cafés de Buenos Aires, faz festas de aniversários, vai ao cinema, ao teatro, a encontros semanais e viaja.

Entonces eso fue que un grupo de mujeres anônimas, empezamos a desfrutar de una hora de ginasio o dos y despues fomos somando (con pilates) en hacer cinta, hacer bicicleta, contudo, ninguna tiene problema de sobrepeso, ni nada. (son todas delgadas), claro, pero no habia hecho ginasio toda nuestra vida, bueno, nos damos animo, por que no veniste, que te pasó, estaba esperando, y no venice en la clase más divertida de venir (Entrevistada B, 69 anos).

A entrevistada B fala de como a relação entre elas tem sido cultivada, a preocupação, logo o cuidado com a "outra" quando alguma falta às aulas. A entrevistada diz que o grupo contribui para aumentar o ânimo de continuar fazendo exercícios. A prática do pilates para essas mulheres, muitas vezes, pode ser interrompida quando a família demanda o tempo dela para o cuidado, geralmente essa demanda está vinculada à saúde do marido ou cuidado com os netos. Alguns estudos sobre mulheres e usos do tempo comprovam que, muitas vezes, as mulheres deixam de praticar atividades físicas devido às demandas familiares, geralmente relacionadas à saúde dos filhos (LÓPEZ et al., 2011; ARAÚJO, 2006). Contudo, quando os filhos já estão crescidos, geralmente elas cuidam de parentes mais velhos (ODDONE, 2014a). Importante ressaltar que essas mulheres cuidam dos netos e do marido, geralmente esses últimos em situação de doença. Nenhuma comentou sobre o ter que cuidar de seus pais mais velhos, sendo esta uma tendência atual na Argentina ${ }^{12}$ : "jovens idosas" que cuidam de "idosas muito idosas" (ODDONE, 2014a).

\footnotetext{
${ }^{12}$ Considerando a expectativa de vida na América Latina, que tem aumentado nos últimos anos, a Argentina apresenta uma realidade favorável, pois seu sistema de seguridade social destaca-se por cobrir 95\% dos idosos com pensões e aposentadorias, além de ter uma população urbana e acesso a hospitais, os idosos ficam mais em suas casas, com pessoas de sua idade, logo pouco vivem em Instituicoes de longa permanência (ODDONE, 2014a).
} 
Para algumas mulheres, o tempo da atividade é extremamente cronometrado, a classe termina às $9 h$, muitas saem no momento do relaxamento, exemplo, a professora, de 65 anos, revelou-me durante a entrevista que trabalha em mais dois estúdios de pilates, além desse que investiguei, e que, no fim da tarde, precisa ficar com seus netos, pois sua filha trabalha fora. Outras mulheres também saem antes de a aula terminar, pois necessitam ir para o trabalho.

A ideia de grupo é muito significativa, durante uma prática, comentam que querem chegar ao fim do ano com mais aprendizados em relação ao corpo, superando dores, fazendo exercícios novos e mais difíceis. A busca de redes de sociabilidade entre idosas também pode ser uma forma de elas evitarem a solidão, quando os filhos não estão mais morando na mesma casa. Um grupo de amigas que se encontram há mais de 10 anos. Um grupo que envelhece junto.

En ginasio hace 12 anos que conecemos nosostras chicas, siempre nos hablamos de nuestra vida, de la salud, de la família. Nos encontramos aca, pero tambien nos encontramos a comer algo a comer, hacer algo, viste, el grupo de las chicas es muy unido y siempre estamos apoyando una a outra. Charlamos mucho, sacamos fotos de los hijos, yo tengo dos hijos y un nieto, hablamos de la vida, nos divertimos, rimos, comemos, cocinamos, siempre llevamos comida, bebida, siempre, ellas ya viajan, tuvo, yo no tuve la oportunidad (Entrevistada D, 63 anos).

À medida que vai se avançando a idade, como o corpo vai apresentando tranformações, os objetivos de cuidado começam a mudar. Os investimentos sofrem alterações, e as idosas fazem atividades para "ter saúde" para poder estar em sociedade, com este corpo destacando-se mais por uma necessidade de ser mais movimento do que imagem para "o outro". (SCRIBANO, 2012).

Verifiquei que essas mulheres conversavam entre elas não só sobre como se cuidavam, mas também recomendavam cuidados. De acordo com elas, essa decisão deve começar cedo, pois os resultados serão conquistados gradativamente, portanto, o cuidado deve começar antes dos 50 anos. Além disso, é importante ter uma boa alimentação e fazer atividades físicas, em que possam trabalhar corpo e mente. Para elas, com a idade, os significados sobre a vida vão mudando, o tempo tende a se tornar um capital. Fazer "las cosas que te gustan", para elas, pode ser a receita para se viver uma "velez tranquila y sana". Mesmo que se cuidando possam ter uma doença, a melhor forma de viver a velhice seria conquistando um equilíbrio sobre o corpo e as emoções. 
Essas mulheres enfatizam o perigo que "parar" de trabalhar significa, bem como não ter atividades, visto que a aposentadoria em suas percepções pode ser o início da morte. Para elas, é preciso ter objetivos, projetos, para não se entregar à morte. Contudo, o problema mesmo são as doenças neurológicas. Conforme a entrevistada C,

\begin{abstract}
$\mathrm{Si}$, las dificuldades son doenças neurológicas, todo mundo habla de las dificuldades, ai quales son las dificuldades, pero vos se jubila y no haces nada es certificado del muerte o enfermidad segura, por que el organismo para, para la mente, para todo (Entrevistada $C, 60$ anos).
\end{abstract}

No entanto, no grupo, há aposentadas que fazem trabalho voluntário, atividades vinculadas à caridade para enfermos e pobres. A entrevistada $\mathrm{B}$ faz dois tipos desse trabalho, um deles em um hospital de Buenos Aires materno infantil, em que ministra uma oficina chamada "la ternura", que é importante para despertar sentimentos em todas as idades e pessoas; segundo ela, também é cozinheira em um projeto que distribui comida nas ruas de Buenos Aires. Para ela, esse tipo de trabalho contribui para "sentirse viva y útil". Complementa dizendo que o envelhecimento contribui para a pessoa ficar "mais sábia" e para despertar valores, como "a gratidão, o perdão, e aceitar as pessoas como elas são". Elas falam de um tipo de tolerância que, com a idade, vai se adquirindo. Contudo, muitas dizem sentir tristeza com o cenário político da Argentina. Pude verificar que elas mostram-se críticas ao feminismo contemporâneo, de modo que, para a grande maioria, ser feminista tornou-se mais moda que consciência sobre quem elas são, fazem críticas ferrenhas às feministas jovens.

É importante ressaltar que essas mulheres, apesar de terem discursos feministas que buscam criticar a opressão do corpo das mulheres, que foram marcados historicamente, elas não se declaram feministas e dizem não gostar de algumas posturas do movimento. Talvez pelo movimento feminista não ter uma pauta centrada no envelhecimento feminino, a experiência que estão vivendo não dialoga com o movimento, logo não se reconhecem nele. Guita Debert (2013), pautando-se em Kathleen Woodward (2003), comenta esse discurso de que, quando se envelhece e se adquire "sabedoria", é problemático. À medida que a sabedoria controla as emoções, pode ser um obstáculo para as ideias feministas as mulheres velhas terem "indignação" para reivindicar os seus lugares no movimento feminista. 


\section{Alguns apontamentos finais}

Comparando o processo de envelhecimento da população com outros países da América Latina, podemos constatar que, na Argentina, o envelhecimento, em termos gerais, tem sido mais favorável, considerando que nesse país grande parte dos/as idosos/as vivem em habitações com pessoas de diferentes gerações ou sozinhos, além de terem maior acesso à seguridade social (ODDONE, 2014b). Contudo, o discurso ideológico de que o ato de envelhecer produz "sabedoria" pode ser limitante para se construir uma reflexão crítica sobre o envelhecimento na contemporaneidade, levando em consideração os diversos fatores que estão em jogo para analisar o envelhecimento a partir de uma perspectiva socioantropológica, fatores que vão desde quando se fala de envelhecimento. Precisamos destacar de que geração de envelhecimento se está falando, considerando que hoje ser idoso pode compreender desde pessoas vistas como na "flor da idade" do envelhecimento, ou seja, 60-65 anos, até homens e mulheres que estão chegando aos três dígitos de idade, ou seja, a geração centenária. Além disso, marcadores sociais como: classe social, raça/etnia, gênero, assim como as situações de violências, nacionalidades e as mudanças nas famílias, entre outros fatores, devem ser considerados em pesquisas que buscam compreender esse tema complexo e interdisciplinar que conduz as ciências humanas e sociais a dialogar com outras áreas do saber.

Esse grupo de mulheres praticantes de pilates analisado traz a reflexividade a partir do pilates, uma prática típica das classes médias contemporâneas, que têm buscado se autoconhecer por meio do corpo (MELUCCI, 1996). Nesse cenário, é importante ressaltar que a grande maioria dessas mulheres critica diretamente os corpos que foram transformados por meio de cirurgias plásticas para agradar "o outro". Para elas, não existem produtos capazes de fazerem "milagres", "todo ilusión construída por el mercado". O cuidado do corpo para essas mulheres tem outro sentido. Para elas, a mulher, quando envelhece, precisa se aceitar e se valorizar, porque o cuidado do corpo não pode estar condicionado ao desejo, "ao outro", assim como corresponder aos padrões de beleza e estética que tomam como referência uma visão eurocêntrica, portanto, colonizadora, que impõe um tipo ideal de mulher para se existir.

Nesse sentido, o grupo de mulheres pesquisado mostra críticas aos modelos de mulheres disseminados pela mídia e o ideal de amor romântico, este que estaria vinculado à ideia de que a mulher só estaria plenamente feliz se estivesse casada ou namorando um homem, portanto, tendo um patriarca protetor (ZANELLO, 2018). Para esse grupo de mulheres argentinas 
pesquisado, o estar acima do peso ou com o metabolismo mais lento pósmenopausa não é encarado com indignação, mas como algo que faz parte do processo do envelhecimento e deve ser compreendido. No entanto, a magreza para elas é algo admirado, por isso preferem estar mais magras, porque dizem se sentirem melhor com seus corpos.

Elas mostram que os maiores momentos de contemplação e cuidado de si são quando estão entre elas. Durante as entrevistas foi constatado como elas têm utilizado diversas práticas de cuidado que vão se configurando em suas vidas de forma gradual, como: movimentar-se antes dos 50 anos, ir aos médicos, fazer o que gosta, mesmo ficando doente, ter equilíbro para encarar a vida e trabalhar para não morrer. Elas trazem nessas recomendações a necessidade do cuidado corporal como um objetivo de vida, sendo o corpo/emoções aquilo que ainda é seu, nesse contexto de perda de referências (MELUCCI, 1996).

Contudo, vale a pena ressaltar que essas mulheres interrompem o autocuidado quando surgem demandas familiares, como o cuidado de netos, ou quando alguém fica doente na família (filho, marido etc.). Evidência que reafirma que o trabalho de cuidado ainda é delegado a elas.

Nesse cenário, o conhecimento de seus corpos apresenta-se como uma forma de registrar as suas presenças no mundo nessa fase da vida, a partir da produção da consciência sobre os seus limites, ou seja, cirurgias não "trarão seus corpos de 30 anos atrás", e suas possibilidades se apresentam como "poder trabalhar e praticar pilates" em uma sociedade movida por grandes fluxos informacionais, especialmente na internet, nas redes sociais, que manifestam a necessidade de as pessoas se encontrarem nessa "torre de babel", em que os discursos sobre os cuidados pautados na lógica do mercado e nos mecanismos de suportabilidade tomaram o cenário da contemporaneidade.

\section{Referências}

ALTMANN, Helena.

(2015). Educação física escolar: relações de gênero em jogo. São Paulo: Cortez.

ARAÚJ0, Emília Rodrigues.

(2006). O doutoramento: a odisseia de uma fase de vida. Lisboa: Colibri.
BARDIN, Lawrence.

(2002). Análise de conteúdo. Lisboa: Edições 70.

BEAUVOIR, Simone de.

(1990). A velhice. Rio de Janeiro: Nova Fronteira. 
BISP0, Raphael.

(2016). Beleza Eterna? A experiência do envelhecimento entre dançarinas eróticas "das antigas" Revista Latinoamericana de Cuerpos, Emociones y Sociedad. vol. 22. Córdoba, p. 52-63.

BOLTANSKI, Luc.

(1979). As classes sociais e o corpo. Rio de Janeiro: Edições Graal.

BOZON, Michel.

(2004). Sociologia da Sexualidade. Rio de Janeiro, Editora FGV.

BRIGUEIR0, Mauro.

(2005). "Envejecimiento exitoso" y "tercera edad": Problemas y retos para la promoción de la salud. Invest Educ Enferm. vol.23. Medellín, p.102-109.

BRITTO DA MOTTA, Alda.

(2002). Envelhecimento e sentimento do corpo. In: MINAYO, Maria Cecília; COIMBRA-JUNIOR, Carlos. Antropologia, saúde $e$ envelhecimento. Rio de Janeiro: Editora FIOCRUZ, p. 37-50.

CONNELL, Raewyn.

(2016). Gênero em termos reais. São Paulo: Nversos.

DEBERT, Guita Grin.

(2009). A dissolução da vida adulta e a juventude como valor. Horizontes Antropológicos vol.1. Porto Alegre, p.49-70.

DEBERT, Guita Grin.

(2013). Feminismo e Velhice. Sinais Sociais. vol.8. Rio de Janeiro, p. 9-86.

DREIER, Katherine.

(1920). Five months in the Argentine. New York, Frederic Fairchild Sherman.

FERNANDES, Maria das Graças Melo; GARCIA, Loreley Gomes.

(2010). 0 corpo envelhecido: percepção e vivência de mulheres idosas. Interface Comunic., Saude, Educ, Botucatu, p.401-412.
FERREIRA, Cristiane Bainchetti et al.

(2007). 0 método Pilates sobre a resistência muscular localizada em mulheres adultas. Motricidadevol. 3. Florianópolis, p.76-81.

FERREIRA, Consuelo; FIGUEIRED0, Marco Antonio de Castro.

(2007). Condicionamento físico: ativação e saúde para mulheres idosas. RBCEH. n.4. Passo Fundo, p. 9-22

GIDDENS, Anthony.

(2005). Sociologia do Corpo: Saúde, Doença e Envelhecimento. In: GIDDENS, Anthony. Sociologia. Porto Alegre, Artmed.

GOFFMAN, Erving.

(1975). Estigma. Rio de Janeiro: Jorge Zahar Editores.

GOLDENBERG, Mirian.

(2010). Estudos sobre gênero, sexualidade e moda na cultura brasileira. São Paulo: Estação das letras e cores.

GUERRA, Juliana de Farias Pessoa.

(2017). Subjetivações femininas na meia-idade: a vivência da menopausa na contemporaneidade. Tese de doutorado, Sociologia, Universidade Federal de Pernambuco.

HIRATA, Helena; GUIMARÃES, Nadya Araujo Guimarães (Eds.).

(2012). Cuidado e cuidadoras: as várias faces do trabalho do Care. São Paulo: Atlas.

IACUB, Ricardo.

(2008). Quem gosta de pessoas idosas? Revista de Psicanálise sociedade e cultura. n.53. Disponivel em: https://www.topia.com.ar/articulos/\%C2\%B F-qui\%C3\%A9n-le-gustan-los-viejos. Acesso em: 26 abr. 2019.

KOGAN, Liuba.

(2005). Performar para seguir performando: la cultura fitness. Anthropologi, San Miguel, p. 151-164. 
KOGAN, Liuba.

(2011). Jóvenes y viejos: ¿el cuerpo como locus de identidad? Revista Latinoamericana de Estudios sobre Cuerpos, Emociones $y$ Sociedad. Córdoba, p. 15-24.

LUCIANI, María Paula.

(2010). Las mujeres argentinas desde la perspectiva de otra mujer: Katherine Dreier en Buenos Aires. La Caja Feminista. Mora. vol.16. Buenos Aires, p. 151-161.

LISDERO, Pedro; BRANDAN, Marcos; PELLÓN, Ignacio; DUBOIS, Daniela.

(2017). Entrenando emociones: reflexiones metodológicas en torno a las "nuevas formas de entrenamientos" y el trabajo. In: GANDÍA, Cláudia et al. Metodologías de la investigación: estrategias de indagación. Ciudad Autónoma de Buenos Aires, Estudios Sociológicos Editora, p.87-104.

LÓPEZ, Elsa et al.

(2011). Mujeres en tensión: la difícil tarea de conciliar familia y trabajo. Población de Buenos Aires vol.8. Buenos Aires, p.7-25.

MARTIN, Emily.

(2006). A mulher no corpo: uma análise cultural da reprodução. Rio de Janeiro: Garamond.

MELUCCI, Alberto.

(1977). "Il corpo ignoto", en Ambrosi, Jean L'enegia dell'umano. Feltrinelli Economica.

MELUCCI, Alberto.

(1996). The playing self: person and meaning in a planetary system. New York, Cambridge University Press.

MELUCCI, Alberto.

(2016). Cuerpos extraños. Ciudad Autónoma de Buenos Aires, Estudios Sociológicos Editora.

MENEZES, Kelly Maria Gomes; FROTA, Maria Helena de Paula.

(2012). Corpos velhos e a beleza do crepúsculo: um estudo sobre os (re) significados da corporeidade na velhice. Revista Latinoamericana de Estudios sobre Cuerpos, Emociones y Sociedad vol.9. Córdoba, p. 0716.
MIRANDA, Leticia Miranda de; FARIAS; Sidney Ferreira.

(2009). Contributions from the internet for elderly people: a review of the literature. Interface - Comunic., Saúde, Educ vol.13. Botucatu, p.383-94.

NARI, Marcela María Alejandra.

(2000). Maternidade Política y feminismo. In: LOZANO, Fernanda Gil; PITA, Valeria Silvina; INI, Maria Gabriela. Historia de las mujeres en la Argentina. Buenos Aires, Taurus, p.197221.

NASCIMENTO, Francisca Denise Silva do.

(2011). Velhice feminina: Emoção na dança e coerção do papel de avó. RBSE - Revista Brasileira de Sociologia da Emoção vol.10. Joao Pessoa, pp. 457-505.

NUNES, Flávia; DUARTE, Regina Tavares Gustavo. (2011). A preponderância do gênero feminino nas atividades físicas para o idoso na Secretaria Municipal de Esportes de Porto Alegre. RBCEH, Passo Fundo vol.8. p. 230243.

ODDONE, Maria Julieta.

(2014a) Ancianas cuidadoras, redes y estrategias en el uso de programas sociales, Cadernos de Pesquisa vol.44. São Paulo, Fundação Carlos Chagas, p.354-377.

ODDONE, Maria Julieta.

(2014b). El desafío de la diversidad en el envejecimiento en América latina; Universidad de Buenos Aires. Facultad de Ciencias Económicas. Plan Fénix; Voces en el Fénixvol.36. p. 82-90.

ORTNER, Sherry.B.

(1979). Está a Mulher para o Homem assim como a Natureza para a Cultura? In: Rosaldo MZ, Lamphere L. (orgs.). A Mulher, a Cultura, a Sociedade., Rio de Janeiro: Paz e Terra.

PINT0, Paula.

(2017). A beleza na velhice ainda é tema tabu, diz antropóloga brasileira. Entrevista. Disponivel em:

https://www.clarin.com/clarin-emportugues/revista/beleza-na-velhice-aindatema-tabu-diz-antropologa- 
brasileira_0_HkFms7q0l.html. Acesso em: 21 abr. 2019.

ROCA, Alejandra. Cuerpo y medios de comunicación.

(2003). Viejas obsesiones y nuevas tecnologías: el cuerpo en revistas femininas argentinas. Cuadernos de Antropología Social vol.17. Buenos Aires, p.139-159.

SCRIBAN0, Adrián.

(2012). Sociología de los cuerpos/emociones. Revista Latinoamericana de Estudios sobre Cuerpos, Emociones y Sociedad vol.10. Córdoba, p.93-113.

SIBILIA Paula.

(2012). El cuerpo viejo como una imagen con fallas: la moral de la piel lisa y la censura mediática de la vejez. Comunicação, Mídia e Consumovol.9. São Paulo, p. 83-114.

SILVA, Maria do Rosário de Fátima e.

(2016). Envelhecimento e proteção social: aproximações entre Brasil, América Latina e Portugal. Serv. Soc. Soc n.126. São Paulo, p. 215-234.

SILVA, Anne Caroline Luz Grudtner; MANNRICH, Giuliano.

(2009). Pilates na Reabilitação: uma revisão sistemática. Fisioterapia Movimento n.22. Curitiba, p. 449-455.

SOARES, Angelo.

(2012). As emoções do care. In: HIRATA, H.; GUIMARÃES, N. A. (Eds.). Cuidado e Cuidadoras: as várias faces do trabalho de care. Sao Paulo: Atlas, p. 44-60.
SONTAG, Susan.

(1972). The double standard of ageing. Nova York, The Saturday Review.

SUAYA, Dulce.

(2015). El cuerpo de la vejez desde una perspectiva de género. aproximaciones desde la vejez de Simone de Beauvoir. Cad. Cedes vol. 35. Campinas. p. 617-627.

TISNÉS, adela; SALAZAR-ACOSTA, Luisa María. (2016). Envejecimiento poblacional en Argentina: ¿qué es ser un adulto mayor en Argentina? Una aproximación desde el enfoque de la vulnerabilidad social. Papeles de Población n. 88. Buenos Aires, p.209-236.

WOODWARD, $\mathrm{K}$.

(2003). Against wisdom: the social politics of anger and aging. Journal of Aging Studies, n. 17, p. 55-67.

YURI, José Alberto; URBANO, Claudio Ariel. (2008). Envejecimiento y género: perspectivas teóricas y aproximaciones al envejecimiento femenino. Revista Argentina de Sociología. n.10, p. 151-169.

ZANELLO, Valeska.

(2018). Saúde mental, gênero e dispositivos: cultura e processos de subjetivação. Curitiba: Editora Appris.

\section{Recebido em}

setembro de 2020

\section{Aprovado em}

abril de 2021 